Bu makaleye atıfta bulunmak için/To cite this article:

GÜLCEMAL, T. (2021). Dış Borç Kullanımı ve Ekonomik Büyüme: Türkiye için Ekonometrik Bir Analiz. Atatürk Üniversitesi Sosyal Bilimler Enstitüsü Dergisi, 25 (Özel Sayı), 194-212.

\title{
Dış Borç Kullanımı ve Ekonomik Büyüme: Türkiye için Ekonometrik Bir Analiz
}

Tuba GÜLCEMAL (*)

Öz: Dış borç, özellikle gelişmekte olan ülkeler için cari ve gelecek dönem gelişmelerinde küresel bir sorundur. Temel ekonomi teorilerine göre diş borç, yatırım ve emek verimliliğ $i$ üzerinde etki yapmalıdır. Gelişmekte olan ülkeler gelişme ve büyüme göstererek bireylerinin refah düzeylerini arttırma, istikrar sağlama, bă̆ımsızlık gibi temel amaçlara sahipken, yüksek cari ve bütçe açılkları verme gibi finansman kaynağı sorunuyla karşı karşıya kalmaktadırlar.

Analizde Türkiye ekonomisinin 1990-2019 yılları arasındaki döneme ait yıllık veriler kullanılarak Gecikmesi Dağıtılmış Otoregresif Model-ARDL, hata düzeltme modeli (VECM) eş bütünleşme ve Toda Yamamoto Nedensellik metotları kullanılmıştır. Analizlerin sonucu dış borç ve ekonomik büyüme arasında bir etkileşimin ve eş bütünleşmenin olduğunu göstermektedir. Bununla birlikte, uzun dönemde ekonomik büyüme ve enflasyon dıs borcu pozitif, ticari açıklı ise negatif olarak etkilemektedir. Ekonomik büyüme'den dış borç yüküne nedensellik ilişkisi varken dış borçtan ekonomik büyümeye nedensellik iliş̧isi olmadiğı tespit edilmiştir. Ticari açıklıktan dış borca doğru bir nedensellik vardır. Enflasyondan dış borca bir nedensellik ilişkisi olması enflasyon yükseldikçe dış borç yükünde bir artış olduğunu fakat dış borç yükü arttığında enflasyonun yükselmediğini ifade etmektedir. Enflasyonla ekonomik büyüme arasında ise çift yönlü bir nedensellik ilişkisi vardır.

Anahtar Kelimeler: Dış borç, ekonomik büyüme, ARDL, Toda Yamamoto Nedensellik Analizi

JEL Sinıflandirmast: C32, F63, H63

\section{External Debt Usage and Economic Growth: Empirical Evidence from Turkey}

Abstract: External debt is a global problem in current and future developments, especially for developing countries. According to main economic theories, foreign debt should have an impact on investment and productivity. While developing countries have basic aims such as increasing the welfare levels of their individuals, ensuring stability and independence by showing development and growth, they are faced with the problem of financing sources such as high current and budget deficits.

In the analysis, Autoregresive Distributed Lag Model-ARDL, Error Correction Model (VECM) co-integration and Toda Yamamoto Causality methods were used by annual data of the Turkish economy between 1990 and 2019 period. The results of the analysis show that there is an interaction and cointegration between external debt and economic growth. Besides economic growth and inflation affect external debt positively and trade openness negatively in the long

*) Dr. Öğr. Üyesi, Sivas Cumhuriyet Üniversitesi İktisadi ve İdari Bilimler Fakültesi Bankacıllk ve Finans Bölümü (e-posta: tgulcemal@cumhuriyet.edu.tr) (D) ORCID ID. https://orcid.org/ 0000-0003-4806-8568

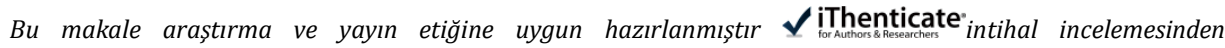
geçirilmiștir. 
run. While there is a causal relationship from economic growth to external debt burden, it has been determined that there is no causality relationship from external debt to economic growth. There is a causality from trade openness ratio to external debt. The fact that there is a causal relationship from inflation to external debt indicates that there is an increase in the external debt burden as inflation increases, but inflation does not increase when the external debt burden increases. There is a bidirectional causality relationship between inflation and economic growth.

Keywords: External debt, economic growth, ARDL, Toda Yamamoto Causality Analysis

JEL Classification: C32, F63, H63

Makale Gelis Tarihi: 06.03.2021

Makale Kabul Tarihi: 14.11.2021

DOI:10.53487/ataunisosbil.892327

\section{Giriş}

Bir ekonomide belirli bir dönemde ölçülen kamu kesimi ve özel kesimin iç ve dış borçlarının toplamının o ekonominin GSYH'sine oranı borç yükünü göstermekte ve toplam borç stoku /GSYH şeklinde ifade edilmektedir.

Mali araçları kullanarak varılması amaçlanan ekonomik hedeflere ulaşmak için yapılan uygulamaların bütünü maliye politikasını oluşturmaktadır. Mali araçlar; vergi, kamu harcamaları, kamu borçlanması araçları olup maliye politikasının alt politikaları da vergi politikası, harcamalar politikası, borçlanma politikası, destekleme politikası, teşvik politikasıdır. Borçlanma politikası gelir ve harcamalar politikaları gibi benzer etkiler yaratsa da geçici bir fon aktarımına yol açtığı için, geri ödenmesi durumunda da ilk etkisinin tersi bir etki yaratarak politika aracı olmaktan çıkarak bir çeşit finansmana aracılık eden bir araç haline dönüşmektedir.

Ekonomik büyüme bir dönemden sonraki döneme üretim miktarındaki reel artıştır. Ekonomik büyüme konusuna dair teorik modeller; Klasik iktisatçıların görüşleri, Keynesyen görüş, Cobb-Douglas Üretim Fonksiyonu Modeli, Harrod-Domar Büyüme Modeli ve Solow Modelidir. Klasik iktisatçılar ekonomik büyüme konusunda çok karamsar yaklaşımlara sahip olmuşlardır. Emeğin ve sermayenin marjinal verimliliğinin azalmasından dolayı, ücretlerin ve kar oranlarının giderek düşeceğini büyüme oranlarının azalacağını ileri sürmektedirler (Parasız, Ekren ve Başoğlu, 2015: 476). Borçlanmayı gelir kaynağı olarak gören Keynesyen görüşe göre büyüme aşamasında kaynak sıkıntısı çeken gelişmekte olan ülkeler için dış borçlanma önemli bir kaynaktır. Harrod-Domar Büyüme Modeli; bir ülkedeki tasarruf-yatırım oranı ile büyüme arasında güçlü bir ilişkinin varlığını ve dış kaynaklar verimli alanlarda kullanıldığı zaman ekonomik büyümenin de gerçekleşeceğini ifade etmektedir. Yatırımlara dönüşen o ekonomide yaratılan veya dışarıdan çekilen tasarruflar artarsa yatırım da artacak ve ekonomi $(G S Y H)$ büyüyecektir. Solow (1957) Neoklasik büyüme teorisinin ve büyümenin kaynakları üzerine daha sonra yapılan ampirik çalışmaların temelini oluşturmuştur (büyüme hesaplaması denklemi ve toplam faktör verimlilik artışı hesaplamasıyla). Solow (1957), büyüme muhasebesi denklemini toplam üretim fonksiyonundan türeterek toplam faktör verimlilik büyümesinin çıktı büyümesine 
katkısını hesaplamak için bir yöntem geliştirmiştir ve bu denklem toplam faktör verimlilik ölçümünün ilk hali olarak bilinmektedir (Jesus \& John, 2020: 12). Klasik görüşü yeniden yorumlayan Neoklasikler, borçlanmanın ülkelerin ekonomik büyümeleri üzerinde eninde sonunda bir düşüş yaratacağı görüşüne dayanarak borçlanmaya karşı çıkmışlardır.

Gelişmekte olan ülkelerde düşük ekonomik büyüme, yüksek işsizlik, eşitsizlik gibi temel sorunlar mevcutken dış borçla finansman, ekonomik büyüme için ikiz açığı ve ikili farkları dengelemede önemli bir kaynaktır. Dış borç ve ekonomik büyüme arasındaki nedensellik ilişkisini inceleyen Reinhart ve Rogoff'un (2010) çalışmalarında dış borcun gelişmekte olan ülkelerde ekonomik büyümenin yavaşlamasının bir nedeni değil bir sonucu olduğu sonucuna ulaşı1mıştır. Gelişmekte olan veya düşük gelir grubunda olan ülkelerin borçlanma ihtiyacı yapısal sorunlardan kaynaklanırken, gelişmiş ülkelerde ise daha ziyade geçici ve dönemsel sıkıntılardan kaynaklanmaktadır. Diğer bir ifadeyle dış borçlanmanın nedenleri ve ekonomik büyüme üzerindeki etkisi, farklı makroekonomik dinamiklere sahip ülkelerde farklılaşabilmektedir. Bu etki pozitif, negatif veya doğrusal olmayan bir ilişki şeklinde olabilir.

\section{Teorik Çerçeve}

Bir ülke ekonomisindeki temel dengeleri gösteren makroekonomik dengeyi ifade eden eşitlik aşağıdaki gibidir: (Eğilmez, 2020b: 271-272)

$$
(\mathrm{S}-\mathrm{I})+(\mathrm{T}-\mathrm{G})=(\mathrm{X}-\mathrm{M})
$$

$\mathrm{Bu}$ eşitlikte üç farklı denge iç içedir: (X-M) ülkenin dış ekonomik dengesini (ödemeler dengesi cari dengeyi) göstermekte iken, (S-I) özel kesimin tasarruf ve yatırım dengesini, ( $\mathrm{T}-\mathrm{G}$ ) bütçe dengesini (kamu kesiminin gelir gider dengesini) göstermektedir. Birçok ülke bu belirtilen dengelerde açık vermekte ve finansmanını ise dış kaynaklar ile sağlamaktadır. Bir ekonominin iç ve dış dengeleri birbirine eşit olmak zorundadır. Eğer iç ekonomik dengenin iki alt dengesi de açık veriyorsa ekonomi cari açık vermekte ve üçüz açıkla karşı karşıya demektir. İç dengelerden biri açık veriyor öteki fazla veriyorsa, cari denge açık veya fazlaya göre şekil alacaktır. İktisat literatüründe kabul gören dış borç ve büyüme arasındaki ilişkileri açıklamaya yönelik yaklaşımlar kısaca aşağıdaki gibidir:

Borçla Büyüme (Debt-Cum Growth) Teorisi: Dış borçlanmanın üstün yönlerini savunan ve dış borcun bir ülke için etkin yatırımların finansmanı için yerel tasarrufların ikamesi olarak görülmesi gerektiğini savunmaktadır. Bu teoriyle ilgili zorluk, yurt içi tasarrufların ve yatırımın iş döngüsünden çıkabilme durumudur (Tornell \& Velasco, 1992: 1219). Bir ülkenin borç miktarı, ekonomik büyümeye katkısı ve ilave borçlanmanın maliyeti ölçüsünde ele alınmalıdır.

Borç Fazlası (Debt Overhang) Teorisi: Modele göre borç sevisinin ülkenin çıtı düzeyinin artan bir fonksiyonu olmasının nedeni ülkenin mevcut borç stokunun geri ödeme kapasitesini aşmasıdır. Krugman (1988) geliştirdiği bu modelde, dış borcun ekonomik büyümede azalışa yol açtığını ifade etmiştir. Eğer ki dış borç gelecekte 
ülkenin geri ödeyebileceğinden daha büyük seviyeye gelmiş ise yerli ve yabancı yatırımcılar gelecekte oluşacak gelir artışı için bugünkü maliyetlere katlanma konusunda isteksiz hale gelecek ve bu durum yatırımdan caymalarına yol açarak, büyümeyi negatif etkileyecektir. Bu durum "Borçlanma Laffer eğrisi" olarak da ifade edilmektedir.

Zamanlar Arası Borçlanma Teorisi: Dış kaynaklardan borçlanmanın ülke içi tasarruf açığını kapatmadaki önemi üzerinde durmaktadır. Buna göre borçlanmadan kaynaklanan bir sermaye artışı meydana gelecek ve ülke daha fazla yatırım yapma olanağına kavuşmuş olacaktır.

Sürdürülebilirlik Teorisi: Bir ülkede dış borçların sürdürülebilirlik seviyesi yurt içi-yurt dışı tasarruflar, plasmanlar ve iktisadi büyüme arasındaki ilişkilere bağlıdır. Alınan dış borçlar ile enflasyona yol açmayan bir iktisadi büyümenin sağlanabilmesi, ülkenin istikrarı, uygulamaya konulacak reformların güvenilirliği, sağlanan plasmanlarla elde edilen kazancın dış borçlanmanın neden olacağı geri ödeme yükünden fazla olmasına bağlıdır. Dış borçların marjinal maliyeti $=$ Dış borçların marjinal faydası denkliği dış borçların optimum seviyesini vermektedir.

Devletlerin dış borçlanmaya yönelmelerinin başlıca sebepleri şöyledir: (Ulusoy, 2013: 58-61) Üretimin gerçekleştirilmesi amaciyla hammadde, ara ve yatırım mallarının zorunlu kıldığı finansman ihtiyacı, sanayileşme ve bununla beraber kalkınmanın büyük bir finansmanı gerektirmesi, ulusal paranın değerinin korunma isteği, dış ticaret ve ödemeler dengesi açıklarının finansmanı, bütçe açıklarının sürekliliğinden kaynaklanan finansman ihtiyacı, vadesi gelmiş borçların ödenmesi, savunma harcamalarının finansmanı şeklinde sıralanabilir. Alınan dış borçların; ekonomik kalkınma üzerinde, ekonominin yapısı üzerinde, gelir dağılımı üzerinde ve ödemeler bilançosu ile döviz kurları üzerinde etkisi vardır.

Kamu kesimi dış borç stoku devletin borçlanmasını yürüten Hazine'nin borç stokuna belediyelerin, kamu iktisadi teşebbüslerinin, fonların ve kamu kesiminin kendi başına borçlanabilen diğer kesimlerinin borç stoklarının eklenmesiyle bulunan miktar anlaşılmaktadır. Bu tutara özel kesimin ve TCMB' nin dış borç stokları da eklendiğinde Türkiye'nin toplam dış borç stok tutarı bulunur. Dış borçlanma ise bir ülkenin kendi para cinsi dışında yabancı para cinsinden alınan borçlar olarak tanımlanmaktadır. Aşağıdaki Tablo 1.'de Türkiye'nin dış borç stokunun kesimlere ve yıllara göre dağılımı görülmektedir. Toplam dış borç yükünün sürekli bir artış trendi izleyerek 2018 yıl sonu dış borç stoku / GSYH' nın \%55,5 oranına yükseldiği fakat brüt dış borç stokunun 2017'den 2018'e 10,9 milyon dolar azalma gösterdiği dikkat çekmektedir. Bunun nedeni de TL'nin 2018 yılındaki büyük değer kaybıdır. 
Tablo 1: Türkiye'nin Brüt Diş Borç Stoku (milyon \$)

\begin{tabular}{|lccccc|}
\hline & $\mathbf{2 0 1 6}$ & $\mathbf{2 0 1 7}$ & $\mathbf{2 0 1 8}$ & $\mathbf{2 0 1 9}$ & $\begin{array}{r}\text { 2020 } \\
\text { 3.çeyrek }\end{array}$ \\
\hline Diş Borç Stoku & 407.920 & 453.679 & 142.758 & 434.503 & 435.121 \\
\hline Kamu Sektörü & 123.324 & 136.172 & 139.85 & 157.100 & 166.428 \\
\hline TCMB & 1.110 & 1.761 & 5.922 & 8.421 & 21.029 \\
\hline Özel Sektör & 283.485 & 315.745 & 296.979 & 268.983 & 247.663 \\
\hline $\begin{array}{l}\text { Diş Borç } \\
\text { Stoku/GSYH }\end{array}$ & $\% 46,9$ & $\% 52,8$ & 055,5 & $\% 57,1$ & $\% 59,1$ \\
\hline
\end{tabular}

Kaynak: T.C. Hazine ve Maliye Bakanlığı İstatistikleri. Erişim Adresi: https://www.hmb.gov.tr/kamu-finansmani-istatistikleri

Kamu kesimi net borç stokuna da, kamu sektörünün brüt iç ve brüt dış borç yükümlülüğü toplamından kamu sektörünün elinde olan finansal varlıkların düşülmesi ile ulaşılmaktadır. Bu tutarın GSYH'ye oranı kamu kesimi net borç yükünü ifade etmektedir (Eğilmez, 2020a: 162). Bir ülkenin dış borcunun GSYH içindeki payına bakılarak o ülkenin borcunun sürdürülebilir olup olmadığı anlaşılabilir. Özel kesimin iç borç yükünün bilinmediği durumlarda da kamu kesiminin toplam borç yükü ile kamu kesimi ve özel kesimin toplam dış borç yükü hesaplamalara ve karşılaştırmalara esas alınmaktadır (Eğilmez, 2020b: 278). Mevsimsel etkilerden arındırılmış cari fiyatlarla Gayri Safi Yurt İçi Hasıla değerleri yıllar itibariye aşağıdaki Tablo 2.'de verilmiştir.

Tablo 2: Mevsim Etkisinden Arındırılmış Cari Fiyatlarla Gayri Safi Yurt İçi Hasıla Değeri (2010-2020)

\begin{tabular}{|ccccc|}
\hline & \multicolumn{4}{c}{ Gayri Safi Yurtiçi Hasıla (Bin TL) Çeyrek Dönemler } \\
\cline { 2 - 5 } & I & II & III & IV \\
\hline 2010 & 273994629 & 285897382 & 296687263 & 311085204 \\
\hline 2011 & 330486977 & 343861070 & 358355727 & 372223841 \\
\hline 2012 & 375884478 & 390484216 & 399992316 & 415118241 \\
\hline 2013 & 428884208 & 452952389 & 467358652 & 474232066 \\
\hline 2014 & 500424319 & 498950337 & 521326732 & 534196439 \\
\hline 2015 & 555652902 & 578339940 & 598147511 & 618800991 \\
\hline 2016 & 628838414 & 647310685 & 635092117 & 715318494 \\
\hline 2017 & 726280402 & 756765449 & 797966523 & 852691894 \\
\hline 2018 & 882476530 & 917009225 & 985413295 & 973416572 \\
\hline 2019 & 1023500261 & 1057417939 & 1093876978 & 1145396049 \\
\hline 2020 & 1186916067 & 1085128020 & 1329149158 & - \\
\hline
\end{tabular}


Kaynak: TÜIK Verisi, 2020 (https://data.tuik.gov.tr)TÜIK verilerine göre ülkemizde 2020 Ocak-Aralık döneminde dış ticaret açığı 49 milyar 915 milyon dolara yükselerek bir önceki yıla göre \%69 artmıştır. Geçtiğimiz yıla göre ihracat \%6,3 azalmışıı, ithalat \%4,3 artış kaydetmiştir. Daha detaylı ele alınacak olursa ihracatın ithalatı karşılama oranı 2019 Ocak-Aralık döneminde \%86,0 iken, 2020 yılının aynı döneminde \%77,2'ye gerilemiştir (https://data.tuik.gov.tr).

\section{Literatür}

Ulusların temel hedefi teorik olarak, ekonomik büyüme ve kalkınmayı sağlayarak yoksulluğu azaltmak ve vatandaşlarının refahını yükseltmektir (Ngo ve Nguyen, 2020). Bu makro hedeflere ulaşmak için bir ülkenin iç ve dış kaynak biriktirmesi gereklidir. Dış borçla finansman; ihracat, doğrudan yabancı yatırımlar ve yabancı yardım gibi ekonomik büyümeyi etkileyen dış kaynaklardan biridir. Neoklasik ve dışsal büyüme modellerinde dış borcun ekonomik büyümeyi negatif olarak etkilediğine değinilmiştir. Nedenselliğin varlığı, nedenselliğin yönü, dış borcun kategorileri ve ekonomik büyüme arasındaki ilişkiler açısından yapılan çalışmalarda birbirinden farklı ve çelişkili bulgular elde edilmiştir. Elde edilen sonuçlar ülkelerin dış açıklık seviyelerine, borcun kullanılma yerlerinin farklı oluşuna ve ekonomik yapının da ülkelere göre farklılık göstermesine göre değişmektedir.

Saraç ve Yüksel (2017) diş borç ve ekonomik büyüme ilişkisini Türkiye ekonomisi için analiz ettiği çalışmada, 2001-2016 yıllarına ait çeyrek verileri kullanarak dış borç stoku ve ekonomik büyüme değişkenleri arasındaki ilişkiyi eşik değer regresyon analizi yöntemini kullanmıștır. Analizde, Türkiye ekonomisinde dış borç seviyesinin ekonomik büyüme üzerinde negatif etkisinin olduğu sonucuna ulaşmıştır. Lof ve Malinen (2014) literatürde tartışmalı bir konu olan devlet borçlanması ve ekonomik büyüme arasındaki ilişkiyi VAR yöntemiyle tahmin etmişlerdir. Gelișmiş olan 20 ülke verisini kullanarak yaptıkları çalışmada borcun büyüme üzerinde daha yüksek borç seviyelerinde dahi büyüme üzerinde güçlü bir etkisi olduğuna dair bir bulguya rastlamazken, negatif korelasyonu açıklayan, büyümenin borçlanma üzerinde tersine negatif bir etkisi olduğuna dair bir bulgu elde edilmiştir.

Bailliu (2000) yaptığı çalışmada dış borç ve büyüme ilişkisini 40 ülke verisini kullanarak 1975-1995 yılları arasını En Küçük Kareler Yöntemi (OLS) ile incelemiştir. Bulgulara göre gelişmiş ülkelerde pozitif, az gelişmiş ülkelerde negatif ilişki ortaya çıkmıştır. Kharusi ve Ada (2018) Umman'da 1990-2015 arası dönemde yıllık veriyle ARDL testi yapmışlardır. Dış borcun ekonomik büyüme üzerinde negatif ve anlamlı bir etkisinin olduğu sonucuna ulaşmışlardır. Dış borç ve büyüme arasında negatif ilişki bulan başka bir çalışma Nguyen vd.'nin (2003) düşük gelir seviyesindeki ülkeleri ele alarak yaptıkları çalışmadır. 1970-1999 yılları arası verisini alarak, sabit etkiler ve GMM yöntemi kullanılarak analiz yapılmıştır. Dış borcun kamu yatırımları üzerindeki etkisiyle büyüme üzerinde dolaylı ve tersine etkileri olduğu sonucuna ulaşılmıştır. Benzer şekilde, Reinhart ve Rogoff'un (2011) 64 gelişmiş ve gelişmekte olan ülkeyi 1914-2010 dönemindeki yıllık veriyi kullanarak yaptı̆̆ı panel veri analizi sonucunda dış borç ve büyüme ilişsisi negatif çıkmıştır. Atique ve Malik'in (2012) 
Pakistan için yaptıkları çalışma 1980 - 2010 yılları arası ilişkiyi En küçük kareler yöntemiyle (OLS) analiz etmiştir. Dış borç miktarının, iç borçlanma miktarıyla kıyaslanırsa ekonomik büyümeyi daha yavaș azalttığı sonucuna ulașılmıștır. Korkmaz (2015) Türkiye'de 2003Q1-2014Q3 arası çeyrek dönem verisiyle yaptığı çalışmada VAR modeli ve Granger nedensellik analizi yöntemlerini kullanmıştır. Çalışmada, ekonomik büyümeden dış borca tek yönlü nedensellik bulunmuştur.

Yine nedensellik ilişkisinin incelendiği Mercan ve Ergen'in (2018) çalışmalarında, 1990-2017 dönemini kapsayan y1llık verilerle VAR modeli ve Granger Nedensellik testi uygulanmıştır. VAR modelinden elde edilen etki - tepki fonksiyonlarına göre, ele alınan dönemde Türkiye'de büyümede meydana gelen bir şoka karşlık dış borç ikinci dönemde negatif tepki vermektedir. Yapılan Granger Nedensellik testine göre de büyümeden dış borca doğru bir nedensellik olduğu görülmektedir.

Benzer şekilde, Kamacı (2016) dış borcun ekonomik büyüme ve enflasyon üzerine etkilerini panel eş bütünleşme ve panel nedensellik analizi yaparak incelemiştir. 1995 - 2014 yılları arasında 6 Orta Asya Cumhuriyeti ve Türkiye'yi ele alarak, dış borçlanmadan büyümeye doğru tek yönlü bir nedensellik tespit etmiştir. Dış borçlanma ile enflasyon arasında ise herhangi bir nedensellik tespit edilmemiştir.

Ampirik çalışmalarda dış borcun ekonomik büyüme üzerindeki non-linear etkisini araştıran çalışmalar da mevcuttur. Pattillo vd. (2002) Latin Amerika, Sahra-Altı Afrika ve Orta Doğu'daki 93 adet gelişmekte olan ülkenin 1969-1998 yılları arasındaki veri setini kullanarak borç ve büyüme arasındaki ilişkiyi araştırmışlardır. OLS, Fixed Effect, System GMM yöntemlerini kullanarak, ortalama bir borçluluk oranına sahip ülkede borç oranını ikiye katlamanın kişi başına büyümeyi \% $0.5-1$ arasında azalttığını, optimal bir borç seviyesinin büyüme üzerinde pozitif bir etkisi olduğu sonucunu elde etmişlerdir. Çalışmada uygun seviyeyi aşan dış borcun, yatırımın hacminden ziyade etkinliğini düşürerek ekonomik büyümeyi azalttığı ortaya konmuştur.

Ayrıca, Imbs ve Ranciere (2005) 87 gelişmekte olan ülke analizinde Laffer eğrisinin non-parametrik bulgusuna dair kanıt elde etmişlerdir. Özellikle, borç fazlasının ortalama değer olarak ihracatın \%200'üne (ve \%140) veya GDP'nin \%60'ına (ve \%40) ulaştığında meydana geldiğini ortaya koymuşlardır. Ayrıca, borç artışı ve ekonomik performans ilişkisinin kurumlarla da ilgili olduğunu, kanunların, devlet yönetiminin etkinliğinin ve bürokratik kalitenin borcun miktarını sınırlandırdığını rapor etmişlerdir.

\section{Veri Seti}

Çalışmada 1990-2019 dönemi için Türkiye'de toplam dış borç stokunun ekonomik büyüme başta olmak üzere bazı diğer makroekonomik göstergeler üzerindeki etkisi test edilmiştir. Ekonomik büyümenin göstergesi olarak GSYH (2010 yılı \$ sabit), toplam dış borcun GSYH'daki \% olarak payı, ihracat ve ithalat toplamının GSYH'daki $\%$ olarak payı ve enflasyon verisi olarak tüketici fiyat endeksi değişkenleri kullanmıştır. Analizde kullanılan değişkenlere ilişkin detaylı bilgiler Tablo 3'de yer 
almaktadır. Kullanılan değişkenler yıllık veridir ve logaritmik formu alınarak analize dahil edilmiştir.

Tablo 3: Değişkenler ve Tanımları

\begin{tabular}{|c|c|c|}
\hline Sembol & Tanım & Kaynak \\
\hline GDP & GSYH Y1ll1k (2010\$ sabit) & $\begin{array}{l}\text { Dünya Bankas1, Ulusal Hesap } \\
\text { Verisi }\end{array}$ \\
\hline DB & Toplam dış borç miktarı (\% GDP) & $\begin{array}{c}\text { Dünya Bankası, Uluslararası } \\
\text { Borç İstatistikleri }\end{array}$ \\
\hline TRADE & İhracat ve ithalat toplamı ( $\%$ GDP) & $\begin{array}{c}\text { Dünya Bankas1, Ulusal Hesap } \\
\text { Verisi }\end{array}$ \\
\hline ENF & Enflasyon (CPI 2010=100) & $\begin{array}{l}\text { IMF, Uluslararas1 Finansal } \\
\text { İstatistikler }\end{array}$ \\
\hline
\end{tabular}

\section{Yöntem}

Dış borçların ekonomik büyüme olmak üzere temel makroekonomik değişkenler üzerindeki etkileri ampirik olarak test edilmişsir. Ampirik analizde kullanılan değişkenlerin kendi aralarındaki dinamik ilişkilerini elde etmek için vektör otoregresyon (VAR) modeli kurulması ve zaman serilerinin durağanlık testlerinin yapılması gereklidir. Durağanlık testi için de Augmented (Genişletilmiş) DickeyFuller (1981, ADF) tarafından geliştirilen birim kök testi ve Philllips ve Perron (1988) tarafından geliş̧irilen birim kök testi yapılmıştır.

\section{A. Geliştirilmiş Dickey-Fuller Testi ve Phillips-Perron Birim Kök Testi}

Durağanlık sağlanamayan zaman serileri ile tahmin edilmiş modellerde sahte regresyon sorunu ortaya çıkmakta ve elde edilen sonuçlarda gerçek bir ilişki bulunmamaktadır. Bir zaman serisinin durağan olması; ortalaması, varyansı ve covaryansının tüm zamanlarda sabit olduğu anlamına gelmektedir (Gujarati, 2005:718). Durağan olmayan serilerde ise birim kök vardır. Birim kök süreci bugünkü bir şokun uzun süre kalıcı etkisi olduğunu ifade etmektedir. Birim kökü test etmede en basit yaklaşım AR(1) modeli ile başlamaktadır: (Wooldridge, 2019:630)

$$
y_{t}=\alpha+\rho y_{t-1}+e_{t}, t=1,2, \ldots
$$

Burada $\mathrm{y}_{0}$, gözlemlenen başlangıç değerini; $\left\{e_{t}\right\}$ 'nin gözlemlenen $y$ 'nin geçmiş değerleri verildiğinde sıfır ortalamaya sahip bir süreci ifade ettiğinde:

$$
\begin{aligned}
& \mathrm{E}\left(e_{t} \mid y_{t-1}, y_{t-2}, \ldots . y_{0}\right)=0 \\
& \left\{e_{t}\right\} \text { 'nin }\left\{y_{t-1}, y_{t-2}, \ldots ., y_{0}\right\} \text { 'ye göre martingale fark dizisi olduğu }
\end{aligned}
$$

söylenmektedir. $\left\{e_{t}\right\}$ 'nin $y_{0}$ 'dan bağımsız olduğu ve sıfır ortalamayla i.i.d olduğu 
varsayılırsa 2.durumu'da sağlamaktadır. $\left\{y_{t}\right\}$ süreci 1. 'yi izlerse ve ancak $p=1$ ise birim kök sürecine sahip olmaktadır. $\alpha=0$ ve $p=1$ ise, $\left\{y_{t}\right\}$ yığılımsız bir rassal gidiş sürecini 2.durumu sağlayan $e_{t}$ şoklarıyla izler. $\alpha \neq 0$ ve $p=1$ ise $\left\{y_{t}\right\}$ yı ğılımlı bir rassal gidiş sürecidir. Buna rağmen sıfır hipotezi altında $\alpha$ 'yı tanımsız bırakmak genel bir yaklaşımdır. Bu yaklaşıma göre sıfır hipotezi $\left\{y_{t}\right\}$ 'nin birim köke sahip olduğunu ifade etmektedir. Birim kök testini uygulamak için 1.denklemin her iki tarafından da $y_{t-1}$ in çıkarılmasıyla ve $\theta=p-1$ tanımlamasıyla elde edilir:

$$
\Delta y_{t}=\alpha+\theta y_{t-1}+e_{t}
$$

2.şartın sağlandığı durumda bu model dinamiktir ve $H_{1}: \theta<0$ alternatif hipotezine karşı $H_{0}: \theta=0$ ' 1 test etmek daha kolaydır. Fakat $H_{0}$ hipotezi altında $y_{t-1} \mathrm{I}(1)$ 'dir ve $\mathrm{t}$ istatistiği için asimtotik standart normal dağılımın temelini oluşturan merkezi limit teoremi uygulanmaz; büyük örneklerde bile t istatistiği yaklaşık standart normal dağılımına sahip değildir. $H_{0}$ hipotezi altında tistatistiğinin asimtotik dağılımı Dickey ve Fuller (1979)'dan sonra Dickey-Fuller dağılımı olarak bilinmektedir. Daha karmaşı dinamiklerle modellerdeki birim kökleri de test etmemiz gerekir. $\left\{y_{t}\right\}$ , $p=1$ ile 1.denklemdeki gibiyse $\Delta y_{t}$ serisel korelasyonsuzdur. İlave gecikmelerle genişletilmiş (3.denklem) denklem ile $\left\{\Delta y_{t}\right\}$ 'nin $\operatorname{AR}(1)$ modelini izlemesi sağlanabilir.

$$
\Delta y_{t}=\alpha+\theta y_{t-1}+\gamma_{1} \Delta y_{t-1}+e_{t}
$$

Burada $\left|\gamma_{1}\right|<1$ 'dir. Bu varsayım $H_{0}: \theta=0$ altında $\left\{\Delta y_{t}\right\}$ 'nin kararlı bir AR(1) modelini izlemesini sağlar. $H_{1}: \theta<0$ alternatif hipotezi altında $\left\{y_{t}\right\}$ 'nin durağan bir AR(2) modeli izlediği gösterilebilir. Süreçteki dinamikleri dikkate almak için denkleme $\Delta y_{t}$ 'nin gecikmelerini ekleyebiliriz. Bu yöntem birim kökün sıfır hipotezini test etmeye benzemektedir.

$$
\Delta y_{t} \text { üzerine } y_{t-1}, \Delta y_{t-1}, \ldots ., \Delta y_{t-p}
$$

5 numaralı regresyonu tahmin ederek önceki gibi $y_{t-1}$ 'in katsayısı $\hat{\theta}$ için t testi yapalım. Dickey-Fuller testinin bu genişletilmiş biçimi Genişletilmiş Dickey-Fuller testi olarak adlandırılmaktadır; çünkü regresyon gecikmeli değişmeler, $\Delta y_{t-h}$ ile 
genişletilmiştir. Gecikmeli değiş̧melerin dahil olması $\Delta y_{t}$ 'de serisel korelasyonu ortadan kaldırmayı hedeflemektedir. Gecikmenin uzunluğu verinin sıklığından etkilenir. Yıllık veri için genellikle bir veya iki gecikme yeterlidir (Wooldridge, 2019:633).

Phillips ve Perron (1988) tarafindan geliştirilen birim kök testi Dickey-Fuller (1979) tarafindan geliştirilen teste oranla daha esnektir. Hata terimleri için herhangi bir kısttlamaya gidilmemiştir. Phillips Perron (PP) tarafından geliştirilen birim kök testinde hata terimlerinin heterojen bir yapı sergilediği görülmektedir. Hata terimleri arasında zayıf bir bağ var olmaktadır. Genişletilmiş Dickey-Fuller (1979) tarafindan geliştirilen birim kök testinde hata terimleri birbirinden bağımsızdır. Ayrıca homojendir. Phillips ve Perron (1988) birim kök testi ile Genişletilmiş Dickey-Fuller (1979) testi arasındaki temel fark bağımlı değişkene ait gecikmeli değerlerin bulunmamasidir.

\section{B. Gecikmesi Dağıtılmış Otoregresif Model (Autoregressive Distributed Lag, ARDL)}

VAR modelinde hangi değişkenin içsel hangi değişkenin dişsal olduğunu belirlemeye gerek yoktur. VAR modeli basit bir yöntemdir, çünkü bütün değişkenler içseldir. Geleneksel OLS yöntemi her bir denkleme ayrı bir şekilde uygulanabilir. VAR modeline göre tahmin yapmak daha karmaşık eş anlı modellere göre birçok durumda daha iyidir. Uygun gecikme uzunluğunun seçimi uygulamada karşılaşılan en büyük sorundur. Ayrıca model I(0) ve I(1) değişkenlerinden oluşuyorsa, yani durağan ve durağan olmayan seriler bir aradaysa veriyi dönüştürmek kolay olmayacaktır (Gujarati, 2004:853).

Serilerin hem düzeyde $\mathrm{I}(0)$ hem de 1 . mertebede durağan $\mathrm{I}(1)$ ve eş bütünleşik olduğu, ele alınan değişkenler arasında uzun dönemli bir denge ilişkisi olduğu durumlarda ARDL (Gecikmesi Dağıtılmış Otoregresif Model) kullanılmaktadır. ARDL, hem bağımlı değişkenin gecikmeli değerlerinin (otoregresif) hem de bağımsız değiş̧kenin gecikmeli değerlerinin açıklayıcı bir değiş̧ken olarak yer aldığı modeldir (Pesaran vd., 2001). Her değişkenin optimal gecikme sayısını elde etmek için tek denklemli VAR tahmini ve gecikme uzunluğu bilgisi kullanılarak gecikme uzunluğu testi yapılır. Daha sonra sınırlandırılmamış Hata Düzeltme (EC) modeliyle tek denklemin tahmini, tahmin edilen gecikme uzunluğu sayısıyla yapılmaktadır.

Geleneksel Johansen (1998) ve Johansen ve Juselius (1990) eş bütünleşme yaklaşımı yerine ARDL tekniğini kullanmanın avantajları, diğerlerinin bir denklem sistemi bağlamında uzun vadeli ilişskileri tahmin etmesiyken, ARDL'nin yalnızca tek bir indirgenmiş denklem kullanmasıdır (Pesaran ve Shin, 1995). Ayrıca, ARDL yöntemi standart eş bütünleşme testinde daha fazla olan spesifikasyonlardan kaçınmaktadır. Spesifikasyonlar, dahil edilecek içsel ve dışsal değiş̧enlerin sayısına ve belirleyici unsurlara dair kararları içermektedir. Dahası, ARDL yaklaşımı standart eş bütünleşme testinde mümkün olmayan, farklı değişkenler için farklı optimal gecikmelerin kullanımına izin vermektedir. Peseran vd. (2001) tarafindan geliştirilen 
sınır testinde kısitsız hata düzeltme modelini ele almaktadır. Bu nedenle diğer uzun dönemli ilişkiyi araştıran modellere göre daha güvenilir sonuçlar vermektedir. ARDL modelinin sıfır hipotezi değişkenler arasında eşbütünleşme ilişkisi yoktur şeklindedir. Alternatif hipotez de değişkenler arasında en az bir adet eşbütünleşme ilişsisi vardır şeklindedir.

\section{Ampirik Bulgular}

Ampirik analize konu olan değişkenlerin kendi aralarındaki dinamik ilişkilerini elde etmek için vektör otoregresyon (VAR) modeli kurulması gerekmektedir. Vektör otoregresyon modeli kurulurken serilerin durağan oldukları yani iktisadi şok yaşamadıkları seviyenin ortaya konulması gerekir. Makroekonomik değişkenlerin iktisadi krizlere maruz kalmaları durumunda kriz olmayan dönemlerde nasıl davrandıkları hakkında fikir yürütmek mümkün değildir. Makroekonomik değişkenler üzerinde iktisadi şokların etkisinin olması ekonometri teorisinde birim kök olarak adlandırılmaktadır. Bu nedenle Dickey-Fuller (1981, ADF) tarafindan geliştirilen doğrusal ve yapısal kırılmaları dikkate almayan birim kök testi ve Phillips Peron birim kök testi yapılmıştır.

Tablo 4: Birim Kök Test Sonuçları

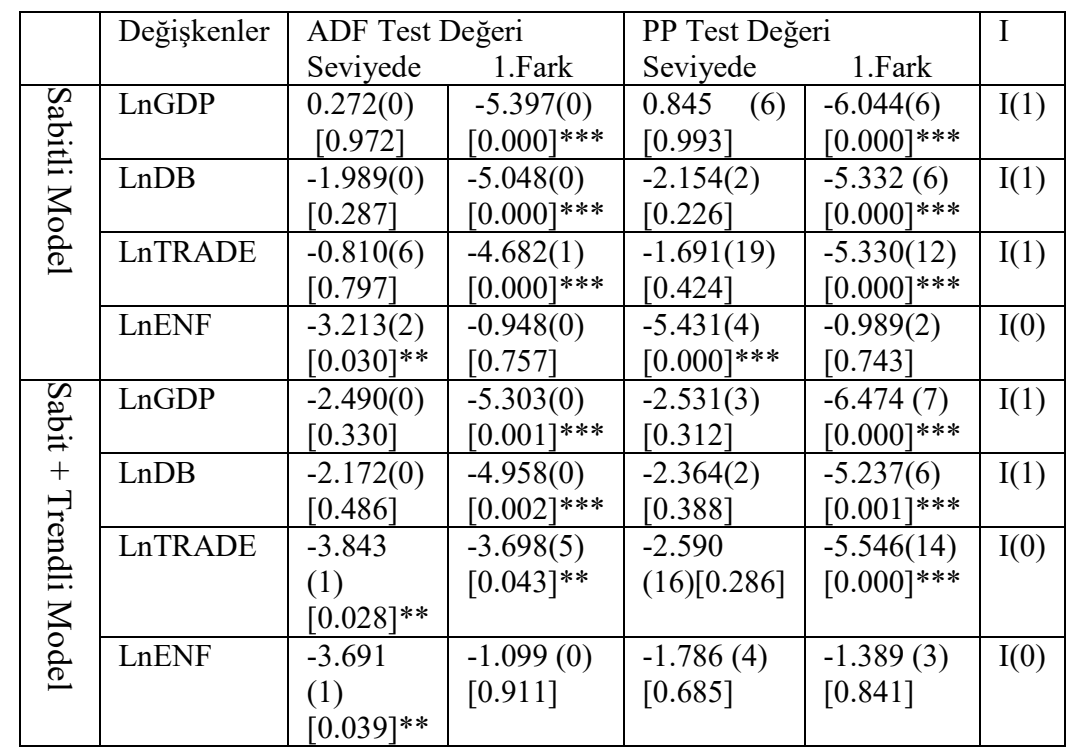

[*] olasıllk değerlerini göstermektedir. ADF Test kritik değerleri sabitte: Mac Kinnon (1996) $1 \%, 5 \%$ ve $10 \%$ için sirasıyla $-3.679322,-2.967767$ ve-2.622989. Sabit \& trendli model için $1 \%, 5 \%$ ve $10 \%$ için de sırasıyla $-4.309824,-3.574244$, 3.221728. PP için sabitte $1 \%, 5 \%$ ve $10 \%$ için sırasıyla MacKinnon test kritik değerleri $-3.679322,-2.967767,-2.622989$. Sabit ve trendli için $1 \%, 5 \%$ ve $10 \%$ için sirasiyla $-4.309824,-3.574244,-3.221728$. PP birim kök testinde Bandwidth: 7 
(Newey-West automatic) Bartlett kernel kullanılmaktadır.

Hem Dickey-Fuller (1981) hem de Phillips-Perron (1988) birim kök test sonuçlarının yer aldığı Tablo 4.'de karar verirken olasılık değerleri kullanılmaktadır. Eğer köşeli parantez içinde verilen olasılık değerleri, \%1 (0.01),\%5 (0.05) ve \%10 (0.1) anlam seviyelerinden büyükse değişkenin birim kök taşıdığı şeklindeki alternatif hipotez kabul edilir. Eğer köşeli parantez içinde verilen olasılık değerleri, \%1 (0.01), \%5 (0.05) ve \%10 (0.1) anlam seviyelerinden küçükse değişkenin birim kök taşımadığı şeklindeki alternatif hipotez kabul edilir. Her iki birim kök test sonuçlarına göre değişkenlerin düzey değerlerinde hem sabitli modelde hem de sabit ve trend değişkeninin dahil edildiği modelde enflasyon serisi hariç seviyede durağan olmadıkları ve birim kök taşıdıkları tespit edilmiştir. Birinci farkları alındığında enflasyon hariç diğer değişkenler durağanlaşmakta ve birim kökler ortadan kalkmaktadır. Hiçbir değişken 1.mertebeden yüksek mertebede entegre olmamıştır ki bu da eşbütünleşme testinin ön koşuludur.

Birim kök testleri akabinde değişkenler arasında uzun dönemli ilişkileri belirlemek amacıyla ARDL eşbütünleşme modeli kullanılmıștır. Değişkenlerin I(0) seviyede ve I(1)'de durağan olmaları nedeniyle ARDL modeliyle devam edilmiştir. İlk olarak değişkenlerin optimal gecikme uzunluklarının bulunması gerekmektedir. ARDL modelinde optimal gecikme uzunluğu Akaike bilgi kriteri kullanılarak 4 olarak bulunmuştur.

Tespit edilmesi gereken bir diğer konu değişkenler arasında uzun dönemli ilișki olup olmadığıdır. ARDL modelinde sıfır hipotezi değişkenler arasında eşbütünleşme ilişkisi yoktur şeklindeyken $\mathrm{H}_{1}$ ise değişkenler arasında en az bir adet eşbütünleşme ilişkisi vardır şeklindedir. Eşbütünleşme ilişkisinin tespitine yönelik istatistikler Tablo 5.'te yer almaktadir.

Tablo 5: Eşbütünleşme İlişkisinin Sınır Testi İle Tespit Edilmesi

\begin{tabular}{|c|c|c|c|}
\hline \multirow{3}{*}{$\begin{array}{l}\bar{g} \\
\frac{0}{N} \\
: 0 \\
0\end{array}$} & Test İstatistiği & Değer & $\mathbf{k}$ \\
\hline & F Bound istatistiği & 6.25 & 3 \\
\hline & & \multicolumn{2}{|c|}{ Kritik Değer Sınırları } \\
\hline \multirow{4}{*}{ 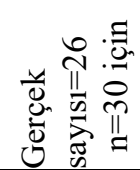 } & Anlam Seviyeleri & $\mathbf{I}(\mathbf{0})$ & I(1) \\
\hline & $10 \%$ & 3.008 & 4.15 \\
\hline & $5 \%$ & 3.71 & 5.018 \\
\hline & $1 \%$ & 5.33 & 7.65 \\
\hline
\end{tabular}

Hesaplanan F istatistiği Peseran vd. (2001) tarafından çalışmalarından yer verilen kritik değerlerle karşılaştırılmaktadır. Hesaplanan F istatistiği alt sınırdan küçükse

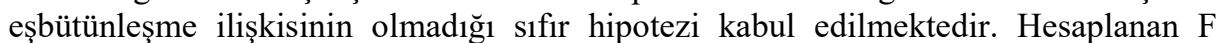
istatistiği üst kritik değerden $\mathrm{I}(1)$ büyük olduğu için $(\mathrm{F}$ ist $=6.25)$ alternatif hipotez $\% 5$ ve $\% 10$ güven aralığında kabul edilmektedir yani uzun dönem ilişki mevcuttur. 
Buna göre değişkenler arasında eş bütünleşme ilişkisi $\operatorname{ARDL}(1,2,4,4)$ olarak tespit edilmiştir. Bu seçilen modele ilişkin sonuçlar Tablo 6'da verilmektedir.

Tablo 6: ARDL $(1,2,4,4)$ Modelinin Tahmin Sonuçları

\begin{tabular}{|l|l|l|}
\hline Değişkenler & Katsayılar & Olasılık değeri \\
\hline LOGDB(-1) & 0.154766 & 0.4061 \\
\hline LOGGDP & -104.4632 & $0.0106^{* *}$ \\
\hline LOGGDP(-1) & 121.2002 & $0.0158^{* *}$ \\
\hline LOGGDP(-2) & 66.33886 & 0.1121 \\
\hline LOGENF & 0.347686 & 0.3722 \\
\hline LOGENF(-1) & -0.352579 & 0.5256 \\
\hline LOGENF(-2) & 0.512911 & 0.3097 \\
\hline LOGENF(-3) & 0.185241 & 0.6667 \\
\hline LOGENF(-4) & -0.563524 & $0.050 *$ \\
\hline LOGTRADE & 0.233428 & 0.3008 \\
\hline LOGTRADE(-1) & -0.573554 & $0.0097 * *$ \\
\hline LOGTRADE(-2) & -0.386259 & 0.1159 \\
\hline LOGTRADE(-3) & -0.580534 & $0.0179 * *$ \\
\hline LOGTRADE(-4) & -0.508226 & $0.0589 *$ \\
\hline C & -5.377272 & 0.0486 \\
\hline $\begin{array}{l}\text { Düzenlenmiş R }{ }^{2}=0.893304 \\
\text { F-istatistik }=15.95069\end{array}$ \\
\hline Prob (F-ist.) 0.000
\end{tabular}

Not:***, ** ve* değerleri sirasıyla \%1 (0.01), \%5 (0.05) ve \%10 (0.1) anlam seviyelerini ifade etmektedir.

Akaike bilgi kriterinin (AIC) en düşük olduğu dış borç stokunun bir dönem gecikmeli, gdp değişkeninin iki dönem gecikmesi, enflasyon değişkeninin dört dönem gecikmesi ve ticaret oranının değişkeninin dört dönem gecikmeli değerinin kullanıldığı model tercih edilmelidir.

Adjusted $\mathrm{R}^{2}$ değerine göre dış borç yükü'ndeki değişmelerin yaklaşık \%89.3'ü modele dahil edilen gdp, ithalat ihracat toplamının gdp'ye oranı ve enflasyon değişkenleri tarafından açıklanmaktadır. Model spesifikasyon testlerine göre Ramsey RESET F-istatistiğinin olasılık değeri 0.70 olup buna göre model kurma hatasının olmadığı bulgusuna ulaşılmıştır. Ayrıca Heteroscedasticity Test (Breusch-PaganGodfrey $\mathrm{F}_{\text {ist }}=0.60$, Prob. $\mathrm{F}=0.81$ ) ) ve Autocorrelation (Breusch-Godfrey Serial Correlation $\mathrm{LM}$ Test $\mathrm{F}_{\text {ist }}=0.54$, Prob.F $=0.59$ ) istatistikleri ve olasılık değerleri dikkate alındığında değişen varyans ve otokorelasyon sorunu bulunmadığı sonucuna ulaşılmıştır. 
Grafik 1: CUSUMSQ Test Grafiği

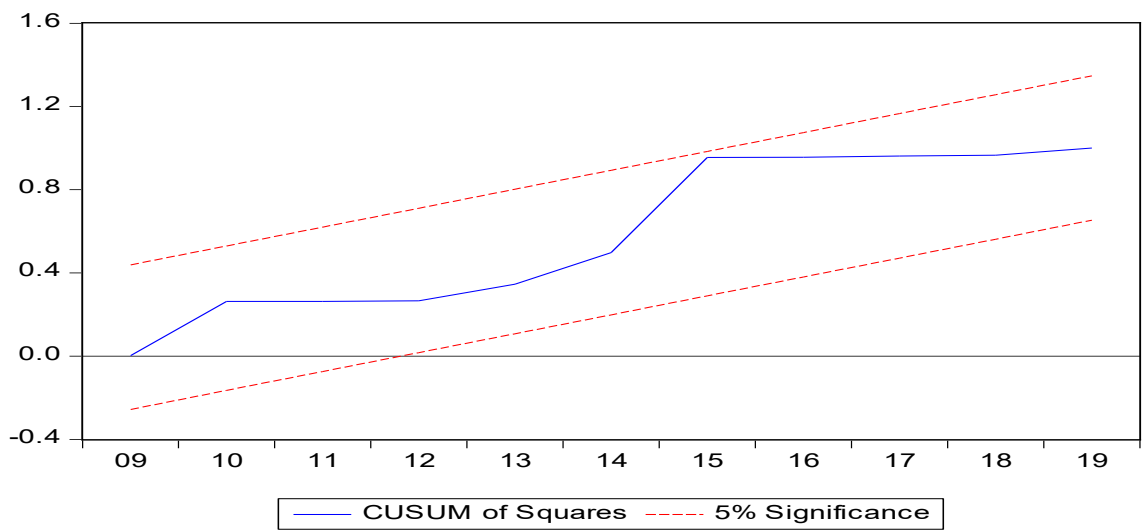

Bahmani-Oskooee ve Ng'ye (2002) göre eğer Grafik 1'de yer alan CUSUM of squares testine göre istatistikler $\% 5$ anlam seviyesinde aralık içinde kalıyorsa kurulan ARDL modelinde serilerin parametre tahminlerinin istikrarlı olduğu şeklindeki sıfir hipotezi kabul edilmektedir. CUSUM test istatistiği incelendiğinde yapısal kırılmaların olmadığını ve hesaplanan uzun dönem katsayıların istikrarlı, durağan olduğu görülmektedir. Bu da uzun dönem ilişkinin var olduğunu bize göstermektedir.

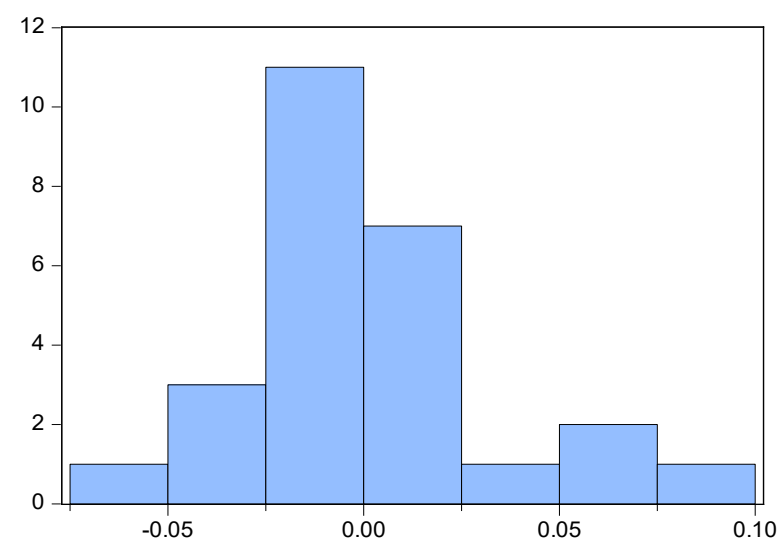

Series: Residuals

Sample 19942019

Observations 26

Mean $\quad-5.60 \mathrm{e}-15$

Median $\quad-0.005816$

Maximum $\quad 0.077888$

Minimum $\quad-0.066161$

Std. Dev. $\quad 0.034112$

Skewness $\quad 0.578284$

Kurtosis $\quad 3.183219$

Jarque-Bera 1.485489

Probability $\quad 0.475806$

Sekil 1: Kalıntıların Normallik Testi

Jarque-Bera Prob. değeri 0.05 'ten büyük olduğu için (0.475) kalıntıların normal dağıldığını göstermektedir.

Tablo 7: ARDL $(1,2,4,4$,$) Hata Düzeltme Modeli ve Uzun Dönem Katsayılar$

\begin{tabular}{|l|l|l|l|}
\hline & Değişkenler & Katsayılar & $\begin{array}{l}\text { Olasıılı } \\
\text { Değeri }\end{array}$ \\
\hline & LOGDB(-1) & -0.856105 & $0.0006^{* * *}$ \\
\hline
\end{tabular}




\begin{tabular}{|c|c|c|c|}
\hline \multirow{14}{*}{$\begin{array}{l}\text { Eşbüttünleşme } \\
\text { Formu }\end{array}$} & LOGGDP(-1) & 0.766984 & $0.0033 * * *$ \\
\hline & LOGENF(-1) & 0.133262 & $0.0292 * *$ \\
\hline & LOGTRADE(-1) & -1.831747 & $0.0106^{* *}$ \\
\hline & D(LOGGDP) & -0.966948 & $0.0105^{* *}$ \\
\hline & D(LOGGDP(-1)) & -0.616322 & $0.1121^{*}$ \\
\hline & $\mathrm{D}$ (LOGENF) & 0.362510 & 0.3493 \\
\hline & D(LOGENF(-1)) & -0.137480 & 0.6363 \\
\hline & $\mathrm{D}($ LOGENF(-2)) & 0.371916 & 0.1991 \\
\hline & D(LOGENF(-3)) & 0.565027 & $0.0491 * *$ \\
\hline & D(LOGTRADE) & 0.226994 & 0.3106 \\
\hline & D(LOGTRADE(-1)) & 1.483996 & $0.0085 * * *$ \\
\hline & D(LOGTRADE(-2)) & 1.095934 & $0.0061 * * *$ \\
\hline & D(LOGTRADE(-3)) & 0.513491 & $0.0559 *$ \\
\hline & $\mathrm{C}$ & -11.35816 & $0.0125 * * *$ \\
\hline \multirow{3}{*}{$\begin{array}{ll}\text { Uzun } & \text { Dönem } \\
\text { Katsayılar } & \end{array}$} & LOGGDP & 0.895900 & $0.0003 * * *$ \\
\hline & LOGENF & 0.155661 & $0.0186 * *$ \\
\hline & LOGTRADE & -2.139630 & $0.0028 * * *$ \\
\hline
\end{tabular}

Not: Sınırlandırılmamış Sabit ve Trendsiz, F Bounds t statistic=6.259193 (alt ve üst kritik değerlere göre $\% 5$ ve $\% 10$ 'da anlamlı). ***, ** ve * değerleri sirasıyla $\% 1$ $(0.01), \% 5(0.05)$ ve \%10 (0.1) anlam seviyelerinde katsayıların istatistiksel olarak anlamlı oldukları seviyeyi göstermektedir.

Uzun dönem katsayılarına göre GDP'nin \%1 artması durumunda dıș borç yükü \% 0.89 artmaktadır. Yine aynı şekilde enflasyonun \%1 artması dış borç yükünü \% 0.15 arttırmakta, ticaretin (ihracat ve ithalat toplamının gdp'ye oranı) \%1 artması durumunda dış borç yükünün \%2.13 azaldığını söylemek mümkündür. Enflasyon \%1 artarsa dış borç yükü \% 0.15 artar, ticaret (ithalat ve ihracat toplamı) \%1 artarsa dış borç \% -2.13 azalmaktadır.

Tablo 8: ARDL Hata Düzeltme Modeli (Kısa Dönem Katsayıları)

\begin{tabular}{|c|c|c|}
\hline Değișken & Katsayı & Olasılık değeri \\
\hline $\mathrm{C}$ & -11.35816 & $0.0002 * * *$ \\
\hline D(LOGGDP) & -0.966948 & $0.0042 * * *$ \\
\hline $\mathrm{D}(\operatorname{LOGGDP}(-1))$ & -0.616322 & $0.0454 * *$ \\
\hline $\mathrm{D}(\mathrm{LOGENF})$ & 0.362510 & $0.0500 * *$ \\
\hline D(LOGENF(-1)) & -0.137480 & 0.5917 \\
\hline $\mathrm{D}(\operatorname{LOGENF}(-2))$ & 0.371916 & 0.1457 \\
\hline D(LOGENF(-3)) & 0.565027 & $0.0152 *$ \\
\hline D(LOGTRADE) & 0.226994 & $0.0847 *$ \\
\hline D(LOGTRADE(-1)) & 1.483996 & $0.0009 * * *$ \\
\hline D(LOGTRADE(-2)) & 1.095934 & $0.0009 * * *$ \\
\hline D(LOGTRADE(-3)) & 0.513491 & $0.0123 * *$ \\
\hline CointEq(-1) & -0.856105 & $0.0001 * * *$ \\
\hline
\end{tabular}


t-Bounds Test İst. $=-5.644908(\mathrm{I}(0)$ ve $\mathrm{I}(1)$ alt ve üst sinır değerlerine göre istatistiki olarak anlamlıdır.

Hata düzeltme katsayısı CointEq (-1) negatif ve istatistiki olarak anlamlıdır. Kısa dönemde oluşabilecek bir dengeden sapmanın (1/0.85) yaklaşık 1.17 yil sonra düzelerek uzun dönem dengesine ulaşacağını bize göstermektedir. Eşbütünleşme ilişkisi ARDL modeli ile incelendikten sonraki aşamada değişkenler arasındaki nedensellik ilişkileri incelenmektedir. Bu amaçla Toda Yamomota Nedensellik analizi yapılmıştır. $\mathrm{Bu}$ doğrultuda serilerin en yüksek entegre olma derecesinin dmax $=1$ olduğuna birim kök testleriyle karar verilmişti. Toda-Yamamoto nedensellik analizi için gerekli olan $\mathrm{p}^{+}$dmax seviyesinin 2 olduğu sonucuna ulaşılmıştır. Bulunan gecikme sayısında otokorelasyon sorunu olup olmadığını test etmek için LM Testi kullanılmıştır. Yapılan VAR analizine göre değişen varyans veya otokorelasyon sorunu olmadığı sonucuna ulaşılmıştır. Olasılık değerlerine bakıldığında, 2. gecikmede otokorelasyon sorununun olmadığına ilişkin sıfır hipotezi kabul edilmektedir.

Şekil 2'e göre AR Karakteristik polinomunun ters kökleri birim çember içerisinde yer almaktadır dolayısıyla tahmin edilen modelin durağanlık koşullarını sağladığını göstermektedir.

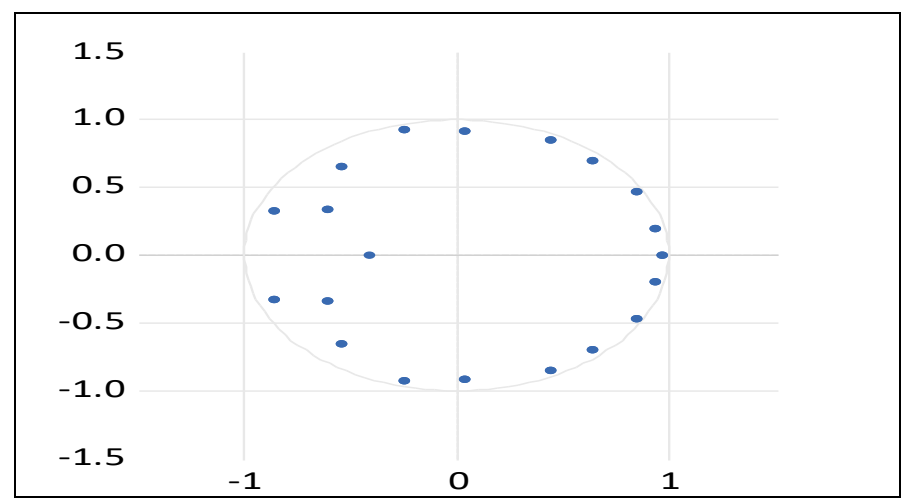

Şekil 2: AR Karakteristik Polinomunun Ters Kökleri

İlgili durum göz önünde bulundurularak Toda Yamomota Nedensellik analizi Wald test istatistiği sonuçları ve olasıılı değerleri aşağıdaki Tablo 9.da sunulmuştur.

Tablo 9: Toda Yamomota Nedensellik Analiz Sonuçları

\begin{tabular}{|l|l|l|l|}
\hline $\begin{array}{l}\text { Nedenselik } \\
\text { Yönü }\end{array}$ & $\begin{array}{l}\text { Wald Test } \\
\text { İstatistiği }\end{array}$ & $\begin{array}{l}\text { Olasılık } \\
\text { Değeri }\end{array}$ & Sonuç \\
\hline GDP $\neq>$ DB & 3.283 & $0.007^{* * *}$ & Nedensellik vardır \\
\hline CPI $\neq>$ DB & 12.05085 & $0.0005^{* * *}$ & Nedensellik vardır \\
\hline TRADE $\neq>$ DB & 4.389160 & $0.0362^{* *}$ & Nedensellik vardır \\
\hline DB $\neq>$ GDP & 0.441762 & 0.5063 & Nedensellik yoktur \\
\hline
\end{tabular}




\begin{tabular}{|l|l|l|l|}
\hline ENF $\neq>$ GDP & 5.332461 & $0.0209^{* *}$ & Nedensellik vardır \\
\hline TRADE $\neq>$ GDP & 0.141282 & 0.7070 & Nedensellik yoktur \\
\hline DB $\neq>$ ENF & 0.877384 & 0.3489 & Nedensellik yoktur \\
\hline GDP $\neq>$ ENF & 5.083304 & $0.0242^{* *}$ & Nedensellik vardır \\
\hline TRADE $\neq>$ ENF & 0.002059 & 0.9638 & Nedensellik yoktur \\
\hline DB $\neq>$ TRADE & 0.004269 & 0.9479 & Nedensellik yoktur \\
\hline GDP $\neq>$ TRADE & 1.603194 & 0.2055 & Nedensellik yoktur \\
\hline ENF $\neq>$ TRADE & 1.626591 & 0.2022 & Nedensellik yoktur \\
\hline
\end{tabular}

*Gecikme uzunluğu AIC bilgi kriterine göre seçilmiştir.

Ekonomik büyümeden diş borç yüküne nedensellik ilişkisi varken diş borçtan ekonomik büyümeye nedensellik yoktur. Nedensellik ilişkisi sadece ekonomik büyümeden diş borca doğru tek yönlüdür. Yani dış borç arttıkça ekonomide bir büyüme beklenmemektedir. Ticaret değişkeninden (ithalat ve ihracat /GDP) diş borca doğru bir nedensellik vardır. Yani ithalat ve ihracat arttıkça dış borçlanma da artmaktadır. Enflasyondan dış borca bir nedensellik ilişkisi olması enflasyon yükseldikçe dış borç yükünde bir artış olduğunu fakat dış borç yükü arttığında enflasyonun yükselmediğini ifade etmektedir. Enflasyonla ekonomik büyüme arasında ise çift yönlü bir nedensellik ilişkisi mevcuttur.

\section{Sonuç ve Öneriler}

Gelişmekte olan ülkelerde ekonomik kalkınmanın sağlanması için dış borcun farklı türlerde ele alındığı görülmektedir. Dış borç, program kredileri, proje kredileri, röfinansman ve bağlı krediler şeklinde kullanılabilir. Alınan dış borcun makro ekonomik etkileri incelendiğinde başta ekonomik büyüme olmak üzere, döviz kurları, dış ticaret, gelir dağılımı, ekonomik yapı üzerinde etkili olduğu görülmektedir.

Çalışmada, Türkiye ekonomisinin 1990 - 2019 yılları arasında kalan yaklaşık 30 yıllık dönemine ait yıllık verileri kullanılarak eş bütünleşme ve nedensellik analizi yapılmıştır. ARDL testi dış borç ve ekonomik büyüme arasındaki uzun dönemli eş bütünleşme analizi için kullanılmıştır. Çalışmada ayrıca, ilişkinin yönünü belirlemek için Toda Yamomota nedensellik analizi kullanılmıştır. Tüm bu analizlerden elde edilen sonuçlar ekonomik büyüme ile dış borç arasında bir etkileşimin ve eş bütünleşmenin olduğunu göstermektedir.

Nedensellik analiz sonuçları, dış borç ve ekonomik büyüme ilişkisinin geçerli olduğunu göstermektedir. Tek yönlü olduğu görülen ilişki alınan kaynakların ekonominin büyümeye yönelik yatırımlarda kullanıldığına dair kanıtlar sunmaktadır. Öte yandan nedensellik ilişkisinin ekonomik büyümeden dış borç miktarına doğru olması ise ekonomik büyümenin Türkiye ekonomisinde dış kaynaklara bağımlı olarak geliştiğini göstermektedir.

Ekonomik büyümeden diş borç yüküne nedensellik ilişkisi varken diş borçtan ekonomik büyümeye nedensellik yoktur. İthalat ve ihracat oranından dış borca doğru bir nedensellik vardır. Enflasyondan dış borca bir nedensellik ilişkisi olması enflasyon yükseldikçe dış borç yükünde bir artış olduğunu fakat dış borç yükü arttığında 
enflasyonun yükselmediğini ifade etmektedir. Enflasyonla ekonomik büyüme arasında ise çift yönlü bir nedensellik ilişkisi mevcuttur.

Büyümenin sağlam bir zemine oturması ve borçlanmanın buna göre yapılması gelecekte ülke ekonomisi açısından pozitif etkide bulunabilecektir. Sürdürülebilir bir büyüme borçlanma açısından da önem arz etmektedir. Alınan borçların verimli alanlara yatırım yapılması ve katma değeri yüksek malların üretilmesi büyümeyi olumlu etkilediği gibi borç yükünü de dengeleyici etkisi olmaktadır.

\section{Kaynaklar}

Atique, R. \& Malik, K. (2012). Impact of domestic and external debt on the economic growth of Pakistan, World Applied Sciences Journal, 20(1), 120-129.

Bahmani Oskooee, Mohsen \& Raymond Chi Wing N.G. (2002). Long- run demand for money in Hong Kong: an application of the ARDL Model. International Journal of Business and Economics, 1(2), 147-155.

Bailliu, J. (2000). Private capital flows, financial development, and economic growth in developing countries. Staff Working Papers, 15, Bank of Canada.

Eğilmez, M. (2020a). Türkiye Ekonomisi. Remzi Kitabevi

Eğilmez, M. (2020b). Makro Ekonomi. (14.basım) Remzi Kitabevi

Felipe, J. \& Mc Combie, J. (2020). The illusions of calculating total factor productivity and testing growth models: from Cobb-Douglas to Solow and Romer. Journal of Post Keynesian Economics, 43(3), 470-513.

Gujarati, D. N. (2005). Temel Ekonometri. Literatür Yayıncılık.

Imbs, J. \& Ranciere, R. (2005). The overhang hangover. The World Bank.

Kamacı, A. (2016). Dış borçların ekonomik büyüme ve enflasyon üzerine etkileri: panel eşbütünleşme ve panel nedensellik analizi. International Journal of Cultural and Social Studies, 2(1), 165-175.

Kharusi, S.A. \& Ada, M.S. (2018). External debt and economic growth: the case of emerging economy. Journal of Economic Integration, 33(1), 1141-1157.

Korkmaz, S. (2015). The relationship between external debt and economic growth in Turkey. Proceedings of the Second European Academic Research Conference on Global Business, Economics, Finance and Banking (EAR15Swiss Conference) ISBN, 971-978.

Lof, M. \& Malinen, T. (2014). Does sovereign debt weaken economic growth? A panel VAR analysis. Economics Letters, 122, 403-407.

Ngo, M. N. \& Nguyen, L. D. (2020). The role of economics, politics and institutions on budget deficit in ASEAN countries. Journal of Asian Finance, Economics and Business, 7(9), 251- 261. https://doi.org/10.13106/jafeb.2020.vol7.no9.251 
Parasız, İ., Ekren, N. \& Başoğlu, U. (2015). Uygulamalı İktisat. Ekin Basın Yayın Dağıtım.

Pesaran, M.H. \& Shin, Y. (1995). An autoregressive distributed lag modelling approach to cointegration analysis. Cambridge Working Papers in Economics 9514, Faculty of Economics, University of Cambridge.

Pattillo, C., Poirson, H. \& Ricci, L., (2002). External debt and growth finance and development. A Quarterly Magazine of the IMF, 39(2).

Reinhart, C. M. \& Rogoff, K. S. (2010). Growth in a time of debt. American Economic Review:Papers and Proceedings, 100, 573-578. http://www.aeaweb.org/articles.php?doi=10.1257/aer.100.2.573

Saraç, T. B. \& Yücel, M. H. (2017). Dış borç ve ekonomik büyüme ilişkisi: Türkiye örneği. Turan: Stratejik Araştırmalar Merkezi, 9(35).

Shkolnyk, I. \& Koilo, V. (2018). The relationship between external debt and economic growth: empirical evidence from Ukraine and other emerging economies. Investment Management and Financial Innovations, 15(1), 387-400

Solow, R. M. (1957). Technical Change and the Aggregate Production Function. The Review of Economics and Statistics, 39(3), 312-320. https://doi.org/10.2307/1926047

Tornell, A. \& Velasco, A. (1992). The tragedy of the commons and economic growth: Why does capital flow from poor to rich countries?. Journal of Political Economy, $100,1208-1231$.

Ulusoy, A. (2013). Devlet Borçları. Celepler Matbaacılık

\section{Internet kaynakları}

https://www.hmb.gov.tr/kamu-finansmani-istatistikleri

https://data.tuik.gov.tr/Bulten/Index?p=Dis-Ticaret-Istatistikleri-Aralik-2020$37412 \&$ dil $=1$

https://data.tuik.gov.tr/Bulten/Index?p=D\%C3\%B6nemsel-Gayrisafi-

Yurt\%C4\%B0\%C3\%A7i Has\%C4\%B1la-III.-\%C3\%87eyrek:-Temmuz--Eyl\%C3\%BCl,-2020-33606\&dil=1 